\title{
Considerations of Interior Design in Domestic Space between Multiplicity of the Concepts and Determination of Constants
}

\author{
Donia M. Bettaieb, Abeer A. Alawad \\ Department of Housing, Interior Design and Furniture, Faculty of Home Economics, King Abdulaziz University, Jeddah, KSA \\ Email:drashad@kau.edu.sa, aalawad@kau.edu.sa
}

How to cite this paper: Bettaieb, D. M., \& Alawad, A. A. (2018). Considerations of Interior Design in Domestic Space between Multiplicity of the Concepts and Determination of Constants. Art and Design Review, 6, 48-60.

https://doi.org/10.4236/adr.2018.61005

Received: January 16, 2018

Accepted: February 23, 2018

Published: February 26, 2018

Copyright $\odot 2018$ by authors and Scientific Research Publishing Inc. This work is licensed under the Creative Commons Attribution International License (CC BY 4.0).

http://creativecommons.org/licenses/by/4.0/ (c) (i) Open Access

\begin{abstract}
Developing a design for a domestic space is associated with the evolution of the needs of both individuals and societies. Hence, the problem has emerged through multiple different types, names, various considerations of its design and many dimensions associated with it, including psychological, social, cultural and economic dimensions. The purpose of this study is to establish a conceptual frame for design considerations regarding domestic space emerges, with the determination of the common constants between different types of domestic space, and reorganizing these constants so an interior designer can apply them can help achieve the desired physical and psychological comfort for the users. This can only occur if we consider that achievement of the physical and psychological comfort for the users is usually a result of the efficiency of design of the Functionality and Aesthetic System of space. Through this study, the conceptual constants of domestic space are determined to include the concepts of Family, Social Relationship/Community, Privacy, Security, Safety, Protection, Comfort/Relaxation/Warmth, wellbeing, Emotional territory, Control and agency, Familiarity, Centrality/Continuity, Freedom, Self-expression/Self-identity/Expression and Personal Identity/Personal character/Practices of personalization and Place attachment. The results of this study can be considered a scientific addition in the field of domestic space design because they discuss the basic concepts associated with the domestic space from the perspective of specialists in the field of interior design. In addition, they represent a rich guide for architects, designers and students in this field and serve as an important reference for education and awareness of society members about the basic concepts associated with domestic space.
\end{abstract}




\section{Keywords}

Interior Design, Domestic Spacing, Home, Functionality, Aesthetic System, Sociological and Psychological Specificities

\section{Introduction}

The multiple types of domestic space and the diversity of standards of design are considered an axiomatic result of the evolution of the needs of users. Many types of domestic space are adopted within all design considerations; above all, the human needs to be in charge of setting the necessities that have been established, such as accommodation, security, safety and comfort. A number of other luxuries are still growing and developing, pursuant to human needs, but they differ and vary, as allowed by the economic, social and cultural situations of their user. Studies have considered many characteristics, whether psychological, social, cultural or economic, as they represent the basic dimensions for what is known as the residential environment or "home" and "the physical and moral structure for domestic space" that we introduce here. However, due to the many studies and different research trends, we find ourselves now in need of building a holistic vision that defines domestic space in an integrated frame, which provides clarification for specialists regarding the constants related to this field as a "physical and moral unit”.

\section{Domestic Space between Emergence and Development}

We cannot address domestic space without referring to human needs as contained in Abraham Maslow's theory or as studying the history of emergence and development of domestic space design. This allows us to determine a concept of domestic space that causes the development of the architectural shape and the development of human needs. These needs increase, according to Maslow, from physiological needs to self-realization needs.

In this context, we can clarify that the need for the human to shelter to protect himself from external environmental factors such as climatic fluctuations and predatory animals while still seeking comfort has caused the emergence of the first architectural work that was known as (home). The human then worked to provide stillness, i.e., relaxation, tranquillity and comfort, by developing facilities and activities both inside and outside the home. The human also worked in accordance with what was clarified by Al Mamouri Sima through his development of the home based on the expression of the social effects that continue to grow and develop in parallel with the evolution of social relationships for a home to become the basic substrate for a network of social relationships (Al Mamouri, 2011). Through this home (Figure 1), the social status is determined, and the class affiliations are thus reflected. 


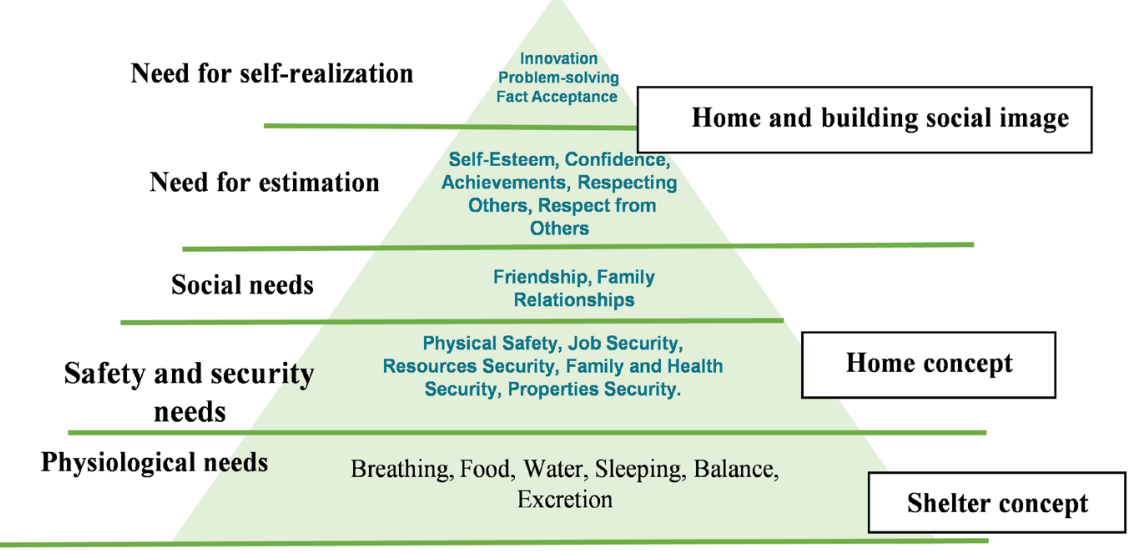

Figure 1. General perception of the evolution of home concept according to Abraham Maslow's Human Needs Order, McLeod, S. (2007).

Architectural design and interior design have played a large role in this context, especially in response to the evolution of human needs and transformation of the home from a one-function idea to the functional diversity concept. This finally led to a bifurcation into basic functions (e.g., sleeping, cooking, eating, living, bathing and defecation) and secondary or supplementary functions (e.g., reception, diversity of bed rooms, diversity of living rooms and bathrooms), which finally other functions for luxury and expression of richness and splendour (e.g., playing hall, swimming pool). In addition, the design played a role in the idea of multifunctionality and utilization of the technological development that is represented in the emergence of the smart home, which reflects the image of a confluence of design thought with the technological capabilities and ability of this intermixture to utilize the space and provide comfort to the users.

Through this course, many names, types, and concepts emerged, and these names, types, and concepts were accompanied by many studies that differed and varied from the perspective of the point in which the "home" has been discussed. Smith considered the concept of home to be greater than just a dwelling (Smith 1994).

\section{Domestic Space between Multiplicity of the Characteristics and Building Conceptual Constants}

In laymen's terms, Lawrence defined a house as a physical unit that provides shelter and protection for its dwellers, mainly to participate in various domestic activities. He covered many aspects, such as the cultural, social, demographic and psychological dimensions (Lawrence, 1987). Other studies focused on social and cultural aspects, attributing all data and information related to the beliefs, customs and traditions of society and the basics of building relationships in society to the home as a shelter. This is in accordance with what was determined by Ibrahim: the basic, individual and family functions are achieved because the home is a field for family relationships, a place for socialization, and a cultural element that reflects the interaction of the individual with his environment 
(Ibrahim, 2008).

Moreover, some studies provided a number of psychological specificities. These studies considered and discussed a number of concepts related to material and non-material needs (Al Mamouri, 2011) and presented substrates of the interaction of the individual with this private spacing, as clarified by Ibrahim, about the presence of a reciprocal relationship between the human and the domestic space in its interactive form, which produces comfort, warmth, specificity and place attachment (Ibrahim, 2008). Furthermore, as Al-Karablieh mentioned that home is the main shelter for comfort and relaxation and is a basic tool for protection and security (Al-Karablieh, 2011), the home thus represents a space in which the basics of communicating with others are built as a nucleus for basis of individuals' behaviours in society.

Many other studies dealt with and discussed concept of the home in accordance with the civilizational indications and expressions reflected by this concept. This includes the work of Al Mamouri, who discussed the human characteristics of the home in the Arab Islamic civilization and considered it to be a nucleus that reflects the principle of the human scale in architectural formation. Additionally, it provides specificity for users through its shape and components, built on extraversion inward and direction of the vision towards the heaven through specificity of the internal yard and principle of the precedence of the internal over the external. The content gives shape and essence to appearance as well as principles of centrality and space gradualism (Al Mamouri, 2011).

It is worth noting that the home has its own tangible and intangible aspects within the framework of its relationship with human requirements and its affiliation to domestic space. In this context, Barros noted that home has a meaning much greater than the material structure that forms it that includes family, security, specificity and society (Barros, 2005). Soaita (2015) determined the basic concepts of the home to add five points to the concept of family 1), as he included 2) comfort and wellbeing; 3) emotional territory, from which feelings of the personal identification and practices of personalization are derived; 4) control and agency territory, which requires actual or virtual ownership of the space; 5 ) the territory that combines sensations and feelings with a material place; and 6) ontological security (Soaita, 2015).

In addition, Fox (2008) has defined the home through five important points as financial investment (for the homeowner); material structure; territory of security, safety, familiarity and control; representation of the personal identification through sense of affiliation and practices of personalization; and social-cultural unity for the family or nation (Fox, 2008).

This delineates that the home has intangible dimensions with many aspects that are not less important than the material aspect that is considered essential.

\subsection{Material Definition of the Home}

Titles that we usually call the domestic space are diverse and different, including "Home", "Dwelling", "House", "Apartment" and "Villa". We do not consider the 
conceptual difference among them, although this conceptual difference often is limited in our minds to the structural and material aspect for the "home". This is generally based on considering one type, style or shape of the residential spaces without exposure to the intangible dimension of this type or that style.

The definition of home includes a simplified classification of a material structure that Al-Karablieh condensed into two main classes: Apartments and Villas (Al-Karablieh, 2011).

It is noteworthy that the name residential apartments are usually applied to dwellings that consist of many floors and have a detached or attached shape. The detached shape is known as buildings or housing towers and skyscrapers that became a phenomenon in many cities, and the attached shape means attached or line dwellings, in which the residential buildings are usually somehow adjacent to one another. A designation of detached homes is given to homes that are composed of one or more floors and have an external space area known as a garden.

Within the framework of the material definition of the home based on these two types, the residential apartments can be defined by considering the principles of a vertical accumulation of the residential units that would produce vertical buildings with many units and floors. This is in the form of independent or attached buildings, compared to detached homes, which are usually in the form of buildings extended on a horizontal level, even if they have many floors to represent in their appearance units separated from each other (Villas). This further considers the homes' gardens and entrances in the form of duplexes and semi-detached houses.

\subsection{Immaterial Definition of the Home and Review of the Characteristics Enumerated by the Residential Environments Studies}

The human needs the home as a moral central point, as he continuously departs from it and returns to it. Hayward described the home as an activity base that provides an actual centre for departure and return (Hayward, 1977). Seamon defined it as the most important centre in the human's daily life (Seamon, 2015), and Ibrahim presented it as the most important basic needs for the human; it is the basic shelter in daily life after frequency or dynamism of living activities (Ibrahim, 2008).

We can interpret the home by what was expressed by Tognoli in his description of the characteristics of Centrality and Continuity (Tognoli, 1987).

While the human needs the home "culturally" as material point that determines his reference location geographically, socially and culturally to consider from this basis "expanded psychological space" and "minimized social space" at the same time.

From this point of view specifically, "the expanded psychological dimension" can be linked to the home as basis of human stability. It is a contributor to structuring and forming behaviours and, in this context, is thus considered a 
material and moral structure detached from the external space and structured as needs of its owner.

While "the minimized social dimension" can be linked, it represents a material facade taken by the human to express himself, his gustatory and cultural tendencies, with the objective of developing his social and material position within the group surrounding him (Dahlin-Ivanoff et al., 2007). From this perspective, the home is considered both a material and immaterial structure that partially overlaps with the environment surrounding it.

In that context, a review of the characteristics listed by residential environments studies is organized in the shadow of this material and intangible information in an attempt to build the basic concepts associated with the home. Table 1 shows these characteristics related to different social and psychological dimensions mentioned above; it also has been designed to build the basics for a conceptual frame for the home and the adoption of the most important points related to its substrates.

The final result of Table 1 is summarized in cognitive perception and built on a collection of the separate concepts and the determination of the common conclusions between the different visions and references of the proposed sources. This perception reflects the common denominators of the characteristics listed by the residential environments studies. We can classify them in this study within the reference data, which provide a source for the fixed design considerations for domestic space.

Based on this, Table 2 represents the most important conceptual constants for home has been designed. In this context, these conceptual constants have been classified pursuant to the determination of the dimension with which they are affiliated, whether psychological, social or both. Thus, both cultural and economic dimensions usually represent two special frames that often are studied in accordance with moral variables, which belong to societies, pursuant to the customs and traditions of their members. They are applied pursuant to type and context of the residential project (adhering to a specified budget belonging to, e.g., the project, space, customs, and traditions).

Here the importance of considering all of these concepts, which the interior designer must plan to achieve in his design for a domestic space and building what is known as a functional and aesthetic system for his project.

The functional and aesthetic system in a domestic space can be defined as the basic system that would convert its own partial functions into the prepared space, with room for all activities (e.g., sleeping, comfort, cooking and bathing) that a user should perform within the framework of the overall function at home.

This context includes the factors that the designer should achieve regarding the balance between the tangible and intangible aspects of the home. Thus, the interior designer usually aims to achieve a balance among the design of the physical appearance for the space, the psychological needs and personal tendencies that should be expressed by this appearance, the social considerations reflected by it and the cultural and economic privacies evoked by it. Interpreting 


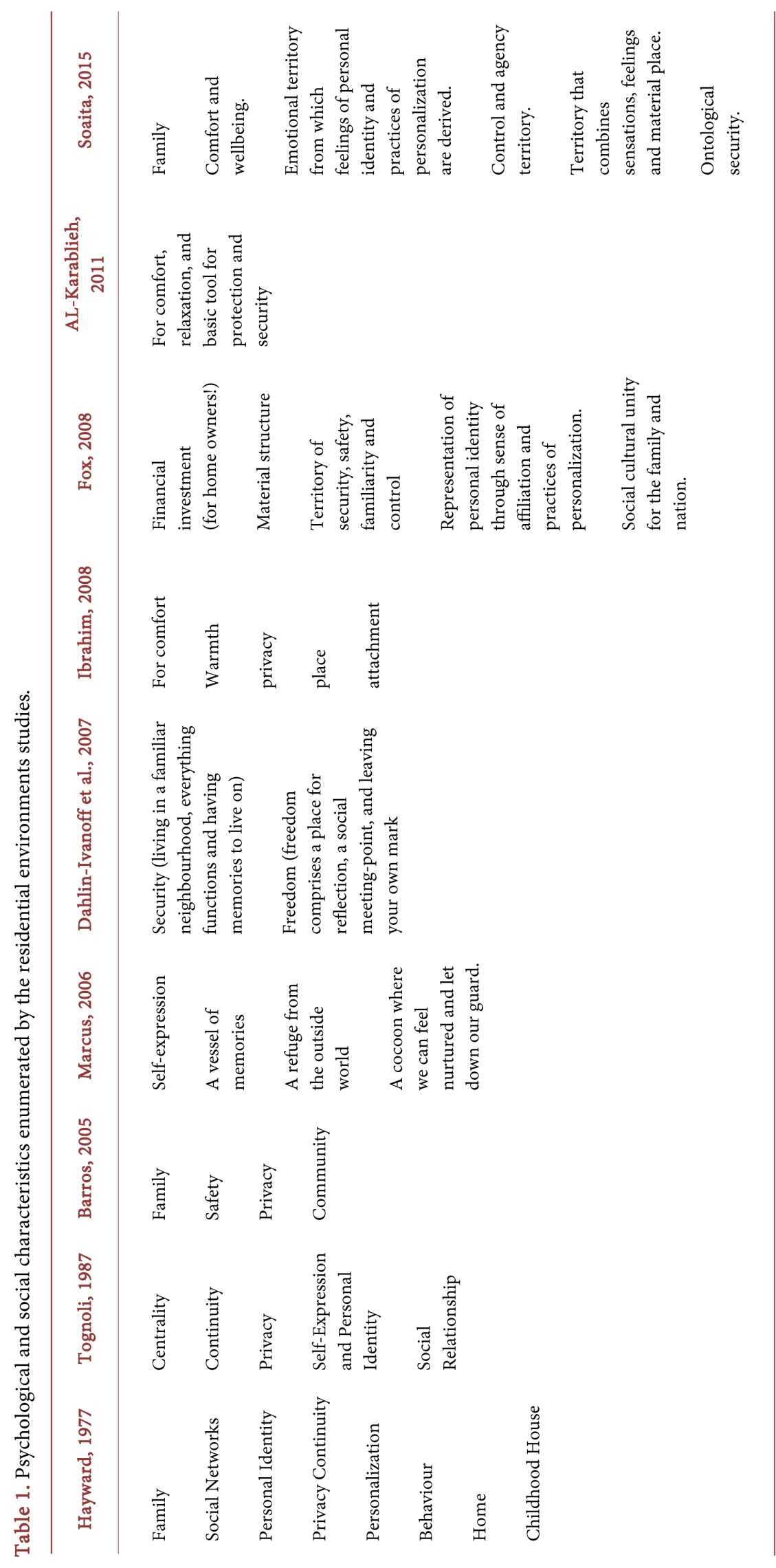


Table 2. Most important conceptual constants of the home.

\begin{tabular}{lcc}
\hline & \multicolumn{2}{c}{ Dimensions Moral } \\
\cline { 2 - 2 } & Psychological & Social \\
\hline Family & $\sqrt{ }$ & $\sqrt{ }$ \\
Social Relationship/Community & \\
Security & \\
ontological security & \\
Safety & $\sqrt{ }$ \\
The basic tool for protection and safety & \\
A cocoon where we can feel nurtured and let down our guard & \\
Comfort/Relaxation/Warmth & $\sqrt{ }$ \\
and wellbeing & $\sqrt{ }$ \\
Emotional territory & $\sqrt{ }$ \\
Control and agency & \\
Familiarity & \\
Centrality/Continuity & $\sqrt{ }$ \\
Freedom (freedom comprises a place for reflection, a social & $\sqrt{ }$ \\
meeting-point, and leaving your own mark) & $\sqrt{ }$ \\
Privacy & \\
Self-expression/Self-identity/Expression and Personnel & \\
Identity/Personal character/Practices of personalization & \\
Place attachment & \\
\hline
\end{tabular}

the tangible and intangible balances for the home in turn requires being both detached from the outside and overlapping with it, thus inviting us to consider the user to be an integral part of this home. The user, in turn, represents the moral and physical element - the human - and embodies the performance of the home and the interactions of its different components within the framework of a reciprocal relationship that produces warmth, comfort, privacy and affiliation, as expressed by Ibrahim.

Based on this, we can define the home as a range of the fulfillments of utilitarian needs that usually appear through its physical and functional structure. This also includes the perceptual sensory expressive needs that are usually met through its functional and aesthetic composition and the sensory influences emanating from them. Thus, a sense or lack of sense of satisfaction, happiness, and comfort is generated inside the user.

\section{The Domestic Space between the Conceptual Constants and Determination of Functions of the Interior Designer}

Within the framework of determining fixed objectives for domestic space design under the specified information and data, Table 3 shows the minimum tasks for the interior designer and the basic objectives for designing the domestic space. 
Table 3. Minimum tasks of the interior designer, considering the most important constant of the home.

\begin{tabular}{|c|c|c|c|}
\hline \multirow{2}{*}{ Tasks of the interior designer } & \multicolumn{2}{|c|}{ Moral dimensions } & \\
\hline & Psychological & Social & \\
\hline $\begin{array}{l}\text { Fulfillment of utilitarian sensory } \\
\text { expressive needs pursuant to the } \\
\text { requirements. }\end{array}$ & \multirow[t]{2}{*}{$\sqrt{ }$} & \multirow[t]{2}{*}{$\sqrt{ }$} & Family \\
\hline $\begin{array}{l}\text { Achievement of the } \\
\text { communication between the } \\
\text { individuals through study of the } \\
\text { distances, functional division and } \\
\text { distribution of elements of the } \\
\text { furniture. }\end{array}$ & & & $\begin{array}{l}\text { Social Relationship/ } \\
\text { Community }\end{array}$ \\
\hline $\begin{array}{l}\text { Achievement of the privacy for } \\
\text { every member of the family and } \\
\text { giving the priority to the parents. }\end{array}$ & $\sqrt{ }$ & $\sqrt{ }$ & Privacy \\
\hline \multirow[b]{2}{*}{$\begin{array}{l}\text { Fulfillment of requirements of } \\
\text { security, safety and psychological } \\
\text { safety. }\end{array}$} & \multirow[b]{2}{*}{$\sqrt{ }$} & \multirow{10}{*}{$\sqrt{ }$} & $\begin{array}{l}\text { Security } \\
\text { ontological security }\end{array}$ \\
\hline & & & $\begin{array}{l}\text { Safety } \\
\text { The basic tool for } \\
\text { protection and safety } \\
\text { A cocoon where we can feel } \\
\text { nurtured and let down our } \\
\text { guard }\end{array}$ \\
\hline \multirow{8}{*}{$\begin{array}{l}\text { Achievement of psychological and } \\
\text { physical comfort. }\end{array}$} & $\sqrt{ }$ & & $\begin{array}{l}\text { Comfort/Relaxation/Warmth } \\
\text { and wellbeing }\end{array}$ \\
\hline & $\sqrt{ }$ & & Emotional territory \\
\hline & $\sqrt{ }$ & & Control and agency \\
\hline & $\sqrt{ }$ & & Familiarity \\
\hline & $\sqrt{ }$ & & Centrality/Continuity \\
\hline & $\sqrt{ }$ & & $\begin{array}{l}\text { Freedom (freedom comprises } \\
\text { a place for reflection, a social } \\
\text { meeting-point, and leaving } \\
\text { your own mark) }\end{array}$ \\
\hline & $\sqrt{ }$ & & $\begin{array}{l}\text { Self-expression/Self-identity/ } \\
\text { Expression and Personnel } \\
\text { Identity/Personal character/ } \\
\text { Practices of personalization }\end{array}$ \\
\hline & $\sqrt{ }$ & & Place attachment \\
\hline
\end{tabular}

\section{Domestic Space with the Designer's Tasks and Rules for Applying Them in Interior Design}

1) Rules for fulfilling the utilitarian and perceptual sensory expressive needs pursuant to the requirements of the context of the project

The concept of utilitarian needs is built on considerations of the distribution, division and juxtaposition of functional elements that aim to achieve utility, communication and service for the family members, pursuant to each member's requirements. Basic utilization elements of home are usually defined in the space 
as related to sleeping, living and eating, and the entrances, passages, stairs, elevator and distribution spaces are considered communication elements. Service elements refer to the kitchen, bathrooms and storeroom, and so on.

This frame is controlled by distribution rules, and a juxtaposition of these elements to zoning vision is usually built on the determination of the different sectors; most areas belong to the calm sector (e.g., areas for sleeping, studying and other activities that require calmness). There is also a living sector (e.g., living and family communication and the other family's common activities) and a service sector (e.g., kitchen, cleaning, maintenance). The division of these sectors, the distribution of different partial spaces for them and the distribution of the furniture elements included in these sectors are built on considerations such as privacy, security, safety and psychological safety. They are common considerations for all of domestic spaces and for all societies.

The concept of perceptual sensory expressive needs is built on the consideration of colour consistency, materials, touches, lighting and the methods of distributing them in spaces. The masses, volumes and elements and aesthetic system that emanate from their composition can express the tendencies, desires and aspirations of the users.

\section{2) Rules of psychological and physical comfort achievement}

Previous studies proved that the quality of a home's internal environment in terms of the design of the internal spacing, distribution of elements of the furniture as well as the temperature, lighting and ventilation can increase the productivity of individuals; this is expressed as comfort (Gabek, 2015, by Ahmed, 2009). In this context, comfort can be defined by the division of physical comfort and psychological comfort.

Psychological comfort is achieved by building sensory perceptual expressive relations such as ventilation, lighting, colours, materials, shapes, masses, volumes and everything related to audiovisual perception and touch. The balance between such elements is considered a necessity that would give a sense of physical comfort.

While physical comfort is achieved by building functional relations between all the physical elements of home and adopting human dimensions as a rule to detail masses, volumes, circulation and equipment, achieving balance among such different elements is considered a necessity that would simultaneously give physical comfort and affirm psychological comfort.

In this context, it is worth mentioning that building the functional and aesthetic systems for domestic spaces generally relies on necessary constants and multiple variables. These constants are represented in privacy, security, safety, psychological safe, communication between individuals, self-identity and self-expression, even if the types, spaces, budgets and tastes are different. Tendencies, desires, aspirations and budget of the user are considered the most important variables.

It also should be noted that achieving psychological and physical comfort for 
the user is an inevitable result of achieving a balance between the tangible and intangible in a dwelling.

3) Rules for achieving interpersonal communication by studying the distances, functional division and elements of furniture

The distances, functional division, distribution of the furniture in the domestic space are built by adopting the immediate zone or personal space zone, which is originally invisible, and a virtual zone that accompanies a person wherever he moves inside the spacing. The zone's measurements change pursuant to considerations such as the context, age and type.

Within this framework, the personal spatial zone contributes to building quality communication between the individuals and organizes the behaviour between them. Functioning the space through its size and distribution of furniture is considered a private position that imposes the treatment method directly on its user. Rationing the distance zones between persons has been brought up by many researchers to organize the relationships between the individuals in the society; these distances have been classified into five main distances (Walters et al., 2005):

- Close Intimate: ranges from 0 to $0.15 \mathrm{~m}$

- Intimate Zone: ranges from $0.15 \mathrm{~m}$ to $0.45 \mathrm{~m}$

- Personal Zone: ranges from 0.45 to $1.2 \mathrm{~m}$

- Social Zone: ranges from $1.2 \mathrm{~m}$ to $3.6 \mathrm{~m}$

- Public Zone: above $3.6 \mathrm{~m}$

It is worth mentioning that these distances express gradations in communication between individuals that range from strong communication between two individuals in a Close Intimate or Intimate Zone, such as a couple or mother and her son, to communicating with less strength when respecting the Personal Zone between friends or family members. This can be converted into an official relationship by adopting the Social Zone, which attributes specific behaviours to the absence, lack or superficiality of communication.

When considering these indications, it is assumed that the designer must achieve communication between the individuals inside the home by dividing the spaces, arranging the furniture and selecting its shapes sizes and positions. For example, selecting a rectangular dining table instead of a square or round shape limits the quality of communication between two individuals. Studying the distance here must consider the distribution of the elements pursuant to the classification of the type of relationships as well as the requirements of the internal environment to reflect important aspects of the interaction of the social dimension with both the emotional and practical aspects.

4) Rules of achieving privacy for every member of the family, with priority given to the parents

Privacy is achieved inside a home at many levels; among these levels, we particularly mention privacy at the perceptual optical visual level and the perceptual voiced audio level. These levels appear when adjusting the physical limits that 
would separate personal and private spaces from the rest of the surrounding spaces through the use of walls, doors, windows and materials that are audiovisual-isolable (calm sector/service sector). Such a functional division is made inside the home in a scientific manner that ensures tangible and intangible independence for all users and provides intimate and personal privacies to all family members living in that home, including the parents. Optical limits and separators can be sufficient for a joint internal space (living sector).

Privacy also appears in the principle of adjacency between partial spaces, such as the adoption of a bathroom that is connected to or very near the parents' suite as a guarantor of the secrecy of their spousal relationships. Privacy is also interpreted in the principle of determination of the distances between the furniture elements through respecting the Personal Space.

5) Rules for fulfilling security, safety and psychological safety requirements

The requirements of security, safety and psychological safety are fulfilled through many considerations, of which the most important are as follows:

Design of the general structure of the home and the use of acute angles in the physical components (walls, furniture).

- Use of materials that are fireproof, anti-ignition and anti-sliding in wet areas such as bathrooms and the kitchen and in walking areas such as passages and stairs.

- Use of automatic systems that protect from robbery and thefts.

- Adoption of emergency exits for vertical buildings that depend on elevators.

- Developing a sense of freedom by organizing the space with reasonable distances and building perceptual communication both among the different elements and between internal and external through the ratios of openings and windows.

- Considering the issue of balance between principles of privacy and social communication on the one hand and the sense of freedom and protection on the other hand.

\section{Conclusion}

Hopefully, this study will help spread awareness of the specific constants used as common denominators among all residential environments, which should always be taken into consideration. Also, it should serve as a guide for all designers looking to achieve tranquillity between the pivotal tangible conscious needs and the intangible needs when designing a residential environment. Lastly, this study should be able to help new designers understand the non-effect of variables in achieving physical and psychological comfort in the domestic space.

\section{References}

Ahmed, M. R. (2009). Study of Effect of Environmental-Technological Integration in Reduction of Structural Operational Cost for the Building. Master Thesis, Irak, Bagdad: 
Department of Architecture, University of Technology.

Al Mamouri, A. S. S. (2011). Humanity of the Arabic Islamic Architecture between Requirements of the Need and Idealism of the Theorization. Iraqi Journal of Architecture, No. 24-23-22, 239-254. https://www.iasj.net/iasj?func=article\&aId=25301

Al-Karablieh, M. A. (2011). Residential Interior Design. Jordan: Al-Mujtamaa Al-Arabi Library for Publishing and Distribution.

Barros, D. B. (2005). Home as a Legal Concept. Santa Clara Law Review, 46, 255.

Dahlin-Ivanoff, S., Haak, M., Fänge, A., \& Iwarsson, S. (2007). The Multiple Meaning of Home as Experienced by Very Old Swedish People. Scandinavian Journal of Occupational Therapy, 14, 25-32. https://doi.org/10.1080/11038120601151714

Fox, L. (2008). Conceptualising Home: Theories, Law and Policies. Oxford: Hart Publishing.

Gabek, M. (2015). Effect of Areas of the Positive and Negative Spaces for the Interior Living Space in the Residential Unit on Comfort of the Occupants. Journal of Babylon University, 23, 139-139.

Hayward, D. G. (1977). Psychological Concepts of "Home". HUD Challenge, 8, 10-13.

Ibrahim, M. I. J. (2008). Architecture of Dwelling ... Indications and Considerations ... Study in Output of Phenomenon of Acculturation. In 7th International Architectural Conference "Housing of the Poor" Problems and Solutions, Egypt.

Lawrence, R. J. (1987). What Makes a House a Home? Environment and Behavior, 19, 154-168. https://doi.org/10.1177/0013916587192004

Marcus, C. C. (2006). House as a Mirror of Self: Exploring the Deeper Meaning of Home. Lake Worth, FL: Nicolas-Hays, Inc.

McLeod, S. (2007). Maslow's Hierarchy of Needs. Simply Psychology, 1.

Seamon, D. (2015). A Geography of the Lifeworld (Routledge Revivals): Movement, Rest and Encounter. Abingdon-on-Thames: Routledge.

Smith, S. G. (1994). The Essential Qualities of a Home. Journal of Environmental Psychology, 14, 31-46. https://doi.org/10.1016/S0272-4944(05)80196-3

Soaita, A. M. (2015). The Meaning of Home in Romania: Views from Urban Owner-Occupiers. Journal of Housing and the Built Environment, 30, 69-85. https://doi.org/10.1007/s10901-014-9396-3

Tognoli, J. (1987). Residential Environments. In D. Stokols, \& I. Altman (Eds.), Handbook of Environmental Psychology (Vol. 1, pp. 655-690). Hoboken, NJ: John Wiley \& Sons.

Walters, M. L., Dautenhahn, K., Te Boekhorst, R., Koay, K. L., Kaouri, C., Woods, S. et al. (2005). The Influence of Subjects' Personality Traits on Personal Spatial Zones in a Human-Robot Interaction Experiment. In IEEE International Workshop on Robot and Human Interactive Communication (pp. 347-352). Nashville, TN.

https://doi.org/10.1109/ROMAN.2005.1513803 